\title{
Cultural Interpretation of Virtual Animation Singer
}

\author{
Chun Zhao \\ School of Art and Design \\ Xihua University \\ Chengdu, China 610039
}

\begin{abstract}
Rising up in Japan, the virtual animation singer is emerging as a shining star with China's two dimensional economy. This paper interprets the unique cultural attributes of the virtual animation singer from science and technology, idol and music culture to find out the underlying reasons of its standing out from many idols and the unique competitive advantages.
\end{abstract}

Keywords—virtual animation singer; science and technology; idol; music

\section{INTRODUCTION}

"The Coming One", a music idol cultivation program launched by Tencent Video targeted at generations after 1995 and 2000, has come to an end few days before. However, the whole program is full of controversy focused on a contestant Hez, a virtual animation singer. Coincidentally, Luo Tianyi and Yan He, two virtual animation singers who already have many fans, held the "First Holographic Concert of Vsinger" in Shanghai Mercedes Benz Cultural Center in June. The first 500 SVIP limited edition tickets of the concert were all sold out within 3 minutes, with a price of $1280 \mathrm{RMB}$. The audience has exceeded a million in Acfun AR live broadcast. These have set the record. The virtual animation singer industry sprung up in Japan has become an important component of China's two dimensional economy, and has penetrated into broader cultural fields from the youth subculture. The multiculture genes of science and technology, idol and music that possess by virtual animation singer are the deep reasons that drive its rapid development.

\section{SCIENCE AND TEChNOLOGY CUlTuRE - BODY AND BASE}

Science and technology has been an important force to promote human progress, the emergence of scientific and technological achievements transformed the appearance of culture to a large extent. The culture transformed by science and technology is called "science and technology culture". It will react to science and technology, and influence economy and politics at the same time ${ }^{[1]}$. The emergence of virtual animation singers can be considered as a complete technological product. Although the science and technology culture it formed has not been able to influence politics, the feedback effect on the science and technology itself and its

This paper is the periodic achievement of the general project (Project Number: xjjg2017079) of the teaching reform project of Xihua University in 2017. influence on the economy have been obvious.

Take the most popular and influential virtual singer software in the world Vocaloid as an example, it is a voice synthesizer technology released by YAMAHA group and an application program based on this technology and developed by the research group led by Kenmochi Hideki in Universitat Pompeu Fabra, Spain. The sound synthesis engine used can splice and process the human sound segments extracted in the frequency, therefore, this technique is classified as a kind of waveform splicing sound synthesis technology ${ }^{[2]}$. Users can directly generate songs by inputting lyrics and notes, and the basic sound data of the songs comes from the dubbing actors. These huge amounts of data are called "sound bank". ${ }^{[3]}$ It is based on the technical method "synthetic engine + sound bank" and the constant technological upgrading that the "VOCALOID Family" ("V" Family for short) represented by Hatsune Miku (Japanese name 初音ミク) can be created. The third generation products have changed the original pattern of only English and Japanese, and added three languages, Chinese, Korean and Spanish. Thanks to this, under the operation of Shanghai Tianshi Henian, the Chinese "V family" represented by Luo Tianyi has become the most popular Chinese virtual animation singer. At present, other families like "U family", "Niao family", MUTA and Sharpkey, etc. have created different Chinese virtual animation singers based on their own technical platform.

In addition to the vocal synthesis technology, the success of the virtual animation singer is inseparable from the development of communication and exhibition technology. The continuous improvement of website technology provides an excellent display and communication platform for the dissemination of related videos, music and other works. In recent years, holographic projection, Augmented Reality (AR for short), and Virtual Reality (VR for short) have sprung up, which drove the virtual animation singer from the two dimensional to the three dimensional world. In the evening of March 9, 2010, Sega Corporation held a concert named "Miku's Day", which made Hatsune Miku as the first virtual singer in the world that held concert using holographic projection. The real and virtual effects gave the audience an unprecedented wonder experience, and made the world see the infinite possibilities of science and technology. Since then, the virtual animation singer is closely linked with the dissemination and performance technology in the forefront of science and technology, showing unprecedented vitality. French scholar Jean Baudrillard put forward the concept of "three sequence of Simulacrum" in the Simulacrum theory, in 
which the third sequence is simulation. He believed that simulation, different from fiction or lie, not only displays absence as presence and imaginary as real, but also weakens any contrast with reality, assimilating reality into its own" ${ }^{\text {[4] }}$. The "cross dimensional" that goes beyond the boundaries between reality and illusion achieved by virtual animation singer through the scientific and technological means has the same purpose.

In addition to the above technologies, the related technologies including 3D visual animation technology, PV production technology and so on all play the indispensable supporting role in prolonging the life of virtual animation singer. It can be said that science and technology is the foundation of virtual animation singers, and the unique culture created by them is also constantly expanding the connotation and extension of science and technology culture.

\section{IDOL CULTURE: LABEL AND DRIVING FORCE}

Idolatry is a unique cultural phenomenon of human beings since ancient times. Idol worship greatly different in various cultures, therefore, it has the dual characteristics of universality and uniqueness. The virtual animation singer can develop from a simple synthesizer to a popular virtual idol, which is a new interpretation of idol culture under the new media environment.

In 2004, a Japanese sound source bank based on Vocaloid voice synthesis engine has been released by CRYPTON FUTURE MEDIA ( "CRYPTON" for short) and was named MEIKO (メイ $ユ$ in Japanese). Compared with the monotonous and serious in the packaging of the previous Vocaloid products, it was endowed with the image of a vibrant short haired girl with a microphone. It was because of this approach that it successfully attracted many amateur producers in addition to electronic music producer, selling 3000 units in the first year. The bug of unnatural pronunciation believed by music producer was also diluted by the virtual anime character and was regarded as its unique pronunciation tag. In 2007, the releasing of Miku products of the second generation completely ignited the virtual animation singer market. Cartoon image of two green ponytails successfully entered the ranks of virtual idols. She not only has a huge fan group, but also held her own concert. Business in various fields were courting her, inviting her to sing the theme song, being spokesperson, playing cameo role and many other business activities, which made her no difference with the real star. This iconic road of operation has also become the best market survival principle of such products.

Although these idols do not really exist, and even are initially the music software packaging materials, they finally get a new life in the strong two dimensional cultural atmosphere. The reasons of being able to break through the tight encirclement of modern society full of idols not only lie in the image designed to meet the otaku's taste for "Adorable" woman, the key is the "Doujun Work". Being parasitized in cyberspace, almost blank background, and the open operation mode that being able to make re-creation according to the fans' personal preferences in story, hobby and personality have become the trump card of the rising. It is the practice that the new media industry using new text, symbol and new operating mechanism to adapt and utilize this technological situation. One of the key effects on fans is that it grants fans more power and places them in the leading role. ${ }^{[5]}$ Although it is inconclusive on the origin of the word "Doujin" (there is no concept of "Doujin" in English, and it is named after the Japanese word "Doujun" pronunciation in Rome), the rising of Fan culture is in Japan centered on animation culture. Hiroki Azuma has proposed in "Animalized Post-Modernity: How does Otaku Affects Japanese Society" that one distinctive characteristic of Otaku culture in post-modernity is re-creation, which is considered as work that is equivalent to the original one. ${ }^{[6]}$ The value of "Doujin" is not only reflected in the consumption side, but also represented in the whole business environment. The original work provides the creative source to Doujin works and Doujin creation constantly make simulacrum ${ }^{[4]}$ and added value to the original work and keep on being consumed, and thus the influence grows day by day [6]. At present, the songs, PV, Dunjin paintings, Dunjin text and so on centered on these virtual idols have been glutted with cyberspace, especially there is a special platform for publishing and exchanging works in the agglomeration area of the two dimensional group. Taking bilibili as an example, "VOCALOID·UTAU" column, specially set under the music channel, includes the content of song creation based on Vocaloid and UTAU engine and other training engines, using various sound sources to create songs. In each column, there will be a large number of creators to participate in it, known as the producer. They wrote songs for their favorite idols with great enthusiasm, and made PV share on their own accounts. This kind of writing pattern is generally called UGC (Usergenerated Content, also known as UCC, User-created Content). Creators are both platform users and content producers, most of whom are amateurs and contribute an overwhelming majority works. It is subdivided into PGC (Professionally-generated Content, also known as PPC, Professionally-produced Content). Some professional producers also participate in the creation, and contribute works in a higher level and with high quality. No matter UGC or PGC, the common ground is that they all start from love, contribute their knowledge voluntarily and are willing to share. On bilibili, Hatsune Miku has 18516 contents, Luo Tianyi has 13067, and Le Tianling and Yan $\mathrm{He}$ also have over 400 contents. The "Ordinary DISCO" created by the "Producer" ilem from Luo Tianyi and Yan He's sound source, has been played for 5.78 million times so far, and the number of reviews has reached more than 157,000 pieces, which number is still rising.

This kind of snowball operation mode has attracted more and more fans to focus on the virtual idols from the two dimension world, and the products that constantly created based on them also made these idols grow and being plump. Fans experience the power of life and achievement of contribution from their attention and creation, therefore, "Developing" idol model has become an important driving force for the development of virtual animation singers. As wrote by Henry Jenkins in his book "Textual Poachers: Television Fans and Participatory Culture" that "fans seem to blur the line between fact and fiction. When they talk about fictional characters, it seems that these characters have a physical existence besides the literal expression. Their attitude 
to the fictional world is like going into a real and touchable world." $"$ What's more, these singers are never old. Although being famous, they never forget their original intention.

\section{Music Culture : LIFE AND SOURCE}

Broadly speaking, the voice of the virtual animation singer belongs to the category of electronic music, but different from each other. Technical characteristics of "synthetic engine + voice source library" has decided that the effect of this music software surely have a more varied style than traditional singers and electronic music. So we see that in the early days of Vocaloid's debut, Meiko has been able to manage pop songs, rock music, jazz, $\mathrm{R} \& \mathrm{~B}$, nursery rhymes, and so on. This technology brings the result that whether the creator is good at any music style, they can achieve their purpose of creation through the software, and even achieve many singing methods and effects that the real singer cannot match. It is not surprising that a number of virtual animation singers sing the music with an extremely fast rhythm and a very high pitch. The key is that when various music styles are added to a virtual character, different fans can find their love from them, and the "omnipotent" aura strengthens the divinity status of the idol identity.

Of course, diversified style is not the whole of the music culture of the virtual animation singers. Everyone has his favorite music, and even more have the creative talent, but most amateur fans do not have the opportunity to cooperate with the real singer. However, through the virtual singer software, they can easily present their works and don't need to worry about searching, nor the copyright issues in use. More importantly, the works can be appreciated by certain audience in the circle formed by the animation singer, even if it is a niche taste, there will be resonant. The popular producer not only enjoys the praise and worship of fans, but also gets certain economic returns through the sale of Dunjin disc. Some works can even be selected as the representative songs in the concert of a singer, and thus receive the spiritual and economic return in a high level. Of course, there are also a few people who enter the wider commercial music field through this circle. It can be said that as a low threshold tool that allows amateur music creators to make complete music works, it has been an excellent springboard for ordinary people to realize their musical dreams, which is an incomparable advantage over other forms of music.

With the increasing popularity of virtual animation singers in the public, the two dimensional image has become the primary carrier of people to recognize it and seek novelty. Like the real stars, they have been attached with the glory of idols. But no matter to what extent they developed, music is their life indeed, and music is the essential source that supports them to move on.

\section{CONCLUSION}

From 2011, Oriental gardenia, known as "China's first virtual Star", appeared on the stage; in the next year, Luo Tianyi was created and has become the most popular Chinese Virtual idol so far; and now $\mathrm{Hez}$ in "the Coming One" received so much controversy when competing with real singers. The influence of virtual animation singer is growing bigger and bigger without any stop. In the future, the growth of the industry will inevitably bring new issues. The unique cultural advantage will still be the biggest capital and bring confidence to singers when facing challenges.

\section{REFERENCES}

[1] Wang Bin. Western Science and Technology Culture and Marx's Political Culture in China [J], Academic Forum, 2009 (02).

[2] Kenmochi Hideki, Oshima Hayato. Singing synthesis system[R],IPSJ SIG Technical Reports, 2008: 51-56

[3] Kenmochi Hideki, Oshima Hayato. VOCALOID - Commercial singing synthesizer based on sample concatenation[C]Interspeech, 2007.

[4] (Fr.) Jean Baudrillard. Simulacraand Simulation [M], Galilee, 2009.

[5] Chen Lin. Fans — Dust Particles Summoned by God, Suzhou University Press, 2012.

[6] (Japan) Hiroki Azuma. Animalized Post-Modernity — How does Otaku Affects Japanese Society [M], Dahong Art Company Ltd., Great Arts Publishing Division, 2015.

[7] Henry Jenkins. Textual Poachers: Television Fans and Participatory Culture [M], Peking University Press, 2016. 